\title{
AUDIT KESELAMATAN JALAN TOL TANGERANG - MERAK
}

\author{
Ni Luh Putu Shinta Eka Setyarini ${ }^{1}$, Michael Gani Virgantara ${ }^{2}$ \\ ${ }^{1}$ Program Studi Sarjana Teknik Sipil, Universitas Tarumanagara \\ Email: shintarachmat@yahoo.com \\ ${ }^{2}$ Program Studi Sarjana Teknik Sipil, Universitas Tarumanagara \\ Email:emji8413@gmail.co.id
}

\begin{abstract}
ABSTRAK
Jalan Tol Tangerang-Merak adalah jalan tol yang menghubungkan Kota Tangerang dan Pelabuhan Merak yang mencakup Tol Cikupa, Balaraja Timur, Balaraja Barat, Ciakande, Ciujung, Serang Timur, Serang Barat, Cilegon Timur, Cilegon Barat, dan Merak. Dengan semakin padatnya ruas jalan tol tersebut akan membuat angka risiko kecelakaan mobil juga semakin meningkat. Dalam upaya meningkatkan keselamatan para pengguna jalan, khususnya jalan tol, maka perlu dilaksanakan Audit Keselamatan Jalan (AKJ). Aspek yang diperiksa dan diamati meliputi aspek geometrik jalan, manajemen lalu lintas, perkerasan, bangunan pelengkap jalan dan perlengkapan jalan. Sebagai hasilnya, diperoleh kesimpulan bahwa dari segi geometrik, secara umum jalan sudah dirancang sesuai dengan ketentuan, namun demikian ada bagian-bagian yang masih memerlukan penyempurnaan. Penelitian ini akan membahas kondisi eksisting jalan Tol Tangerang-Merak berdasarkan pengamatan langsung. Aspek yang ditinjau adalah aspek geometrik, perkerasan, dan bangunan pelengkap jalan seperti Rambu, Marka dan Median jalan. Pada akhirnya, akan didapatkan daerah rawan kecelakaan pada ruas tol Tangerang-Merak dengan analisis perbandingan dari data pengamatan langsung, dan data kecelakaan lalu lintas.
\end{abstract}

Kata Kunci: Jalan Tol; Pelengkap Jalan; Daerah Rawan Kecelakaan; Audit Keselamatan Jalan

\section{ABSTRACT}

Tangerang-Merak Toll Road is a toll road connecting Tangerang and Merak Port, which includes Cikupa Toll Road, East Balaraja, West Balaraja, Ciakande, Ciujung, East Serang, West Serang, East Cilegon, West Cilegon, and Merak. With the more congested, will make the risk of car accidents also increased. In an effort to improve of road safety, especially toll roads, a Road Safety Audit (AKJ) is needed. Aspects examined and observed include geometric, traffic management, pavements, street furnitures and complementary buildings. As a result, it is concluded that in geometric aspect, in general has been designed in accordance with the provisions, but nevertheless there are parts that still require improvement. This research will discussed the existing condition of Tangerang-Merak Toll Road based on direct observation. The aspects reviewed are geometric, pavement, street furnitures and road complementary buildings such as Signs, Markings and Median roads. In the end, accident-prone areas will be obtained on tangerangmerak toll road with a comparison analysis of direct observation data, and traffic accident data.

Keywords: Toll Road; Street funitures; Accident Prone Areas; Road Safety Audit

\section{PENDAHULUAN}

Pelanggaran lalu lintas yang cukup tinggi serta kepemilikan kendaraan pribadi yang semakin hari semakin meningkat, hal ini secara tidak langsung dapat memicu terjadinya kecelakaan lalu lintas. Dengan pengalaman yang dimiliki oleh negara maju untuk mengatasi defisiensi keselamatan jalan seringkali tidak diterapkan di Indonesia karena hampir 92\% terjadinya kecelakaan diakibatkan oleh faktor manusia, 5\% oleh faktor kendaraan dan 3\% oleh infrastruktur jalan dan lingkungan (Fuller 2005 dan Mulyono 2008c; 2009). Interaksi antara manusia dan kondisi permukaan jalan memberikan kontribusi hampir 35\% terhadap terjadinya kecelakaan di jalan raya (Treat, et al., 1977), yang kemudian berkurang menjadi 24\% (Austroads, 2002). Kecelakaan di daerah perkotaan 
mengkategorikan lebih jauh faktor kesalahan manusia yang dipacu oleh keterbatasan jarak pandang ketika mengemudikan kendaraan sehingga hampir 30\% dari 45\% kasus kecelakaan disebabkan oleh manusia (Austroads, 2002).

Dalam dua tahun terakhir ini kecelakaan lalu lintas di Indonesia oleh Badan Kesehatan Dunia (WHO) Tahun 2018 dinilai menjadi pembunuh terbesar ketiga, dibawah penyakit jantung koroner dan tuberkulosis/TBC. Tingginya angka kecelakaan lalu lintas mendorong segera dilakukannya penggalangan seluruh komponen bangsa untuk bersama-sama menekan angka kecelakaan di Indonesia.

Indonesia memiliki wilayah daratan luas, sarana infrastruktur jalan terbilang panjang termasuk Jalan Tol Trans Jawa. Jalan Tol terus di bangun untuk menjadi solusi mengurang kepadatan di jalan arteri (Radiansyah, et al. 2017). Namun dengan semakin meningkatnya aktifitas antar kota dari penduduk kepadatan juga terjadi di jalan Tol yang menimbulkan kecelakaan. Dari data BPS tahun 2018, sedikitnya kematian akibat kecelakaan lalu lintas sepanjang tahun 2018 menelan korban mencapai 27.910 korban jiwa dengan angka kecelakaan lalu lintas tercatat sebanyak 103.672. Sementara korban luka ringan pada tahun ini lebih banyak dari tahun lalu yakni sekitar 17 persen peningkatannya dari 4492 di tahun 2017 menjadi 5237 korban di tahun ini. Pemikiran bahwa kesalahan manusia lebih banyak dipicu oleh kondisi sistem lalu lintas dan jalan raya pada saat-saat tertentu yang tidak dapat diantisipasi (hazard surprised) oleh pengguna jalan, sehingga pemasangan rambu dan marka sangat berguna untuk peringatan dan antisipasi awal (Idalin, et al. 2018; Firgian, et al 2014 dan Duddu, V. R., et al 2019). Sebagai contoh, penelitian di Universitas Leeds pada tahun 1989 (Carsten, 1989) atas kecelakaan di daerah perkotaan mengkategorikan lebih jauh faktor kesalahan manusia yang dipicu oleh keterbatasan jarak pandang ketika mengemudikan kendaraan yaitu hampir $30 \%$ dari $45 \%$ kasus yang disebabkan faktor manusia.

Salah satu cara yang mudah dan ekonomis untuk meningkatkan keselamatan jalan adalah dengan memasang fasilitas perlengkapan jalan. Apabila fasilitas tersebut dipasang sesuai dengan tujuan dan tempatnya, serta aturannya ditegakkan dengan tegas, maka cara ini akan menjadi sangat efektif dan efisien. Tentunya dalam pengadaan dan pengoperasian fasilitas perlengkapan jalan khususnya di jalan tol diperlukan koordinasi antara Kementerian Pekerjaan Umum sebagai penyelenggara jalan (PERMEN PU no. 20 tahun 2010) dengan Kementerian Perhubungan sebagai penyelenggara fasilitas perlengkapan jalan (PM 82 tahun 2018), dan Operator Jalan Tol (Jasa Marga) sebagai pengatur operasional dan pemeliharaan jalan, serta Kepolisian sebagai penegak peraturan. Dalam hal ini koordinasi dan integrasi antar instansi (5 pilar dalam Rencana Umum Nasional Keselamatan/RUNK) sangat diperlukan. Menurut Vardaki, et al., 2018, keselamatan adalah bagian integral dari semua keputusan dan integrasi birokrasi yang mempengaruhi jalan dan sistem dari infrastruktur.

Tangerang sebagai salah satu wilayah satelit dari ibukota Jakarta mengalami pertumbuhan yang sangat pesat di berbagai sektor khususnya dari sektor pertumbuhan penduduk, ekonomi, dan perindustrian. Hal ini dibuktikan dengan semakin meningkatnya nilai investasi di kota Tangerang dan perkembangan infrastruktur yang terus membaik (Kabag Perekonomian Pemkot Tangerang, Muhammad Noor, 2011). Jalan Tol Tangerang-Merak adalah jalan tol yang menghubungkan Kota Tangerang dan Pelabuhan Merak. Jalan tol ini melintasi Kota Tangerang dan Kabupaten Tangerang, Kabupaten Serang dan Kota Serang dan Kota Cilegon. Jalan Tol ini juga adalah kelanjutan dari Jalan Tol Jakarta-Tangerang. Kilometer 0 ada di Tomang, Jakarta, dan berakhir di 
Kilometer 98 di Merak. Panjang jalan tol ini adalah $72 \mathrm{~km}$. Operator tol ini adalah PT Marga Mandalasakti (MMS). Berdasar data PJR, kasus kecelakaan yang terjadi di Tol Tangerang Merak sepanjang 2018 sebanyak 913 kasus dengan korban sebanyak 386 orang dengan rincian 25 di antaranya meninggal dunia, 155 luka berat dan 206 luka ringan. Sedangkan pada 2017, tercatat sebanyak 911 kasus dengan jumlah korban 28 meninggal dunia, 160 luka berat dan 255 luka ringan. Roseily (2013), membahas tentang tol Tangerang-Merak mengenai karakteristik kecelakaan lalu lintas pada Ruas Jalan Tol Tangerang-Merak, kejadian kecelakaan pada ruas jalan Tol Tangerang-Merak setiap tahunnya menunjukkan angka yang cukup tinggi. keselamatan lalu lintas. Hal tersebut ditunjukkan pada tabel 1 yang memuat jumlah kecelakaan yang terjadi di Tol Tangerang - Merak sesuai dengan data dari pengelola yaitu PT. Marga Mandala Sakti (MMS) tahun 2018.

Tabel 1. Jumlah Kecelakaan di Jalan Tol (Tahun 2018)

Sumber Tabel: PT Marga Mandalasakti (MMS)

\begin{tabular}{cccccc}
\hline Nama Ruas Jalan & \multirow{2}{*}{ Km } & \multirow{2}{*}{ Total Kecelakaan } & \multicolumn{3}{c}{ Tingkat Keparahan } \\
\cline { 3 - 6 } & & & MD & LB & LR \\
\hline Balaraja Barat - Cikande & $38.90-52.20$ & 106 & 6 & 20 & 57 \\
\hline Cikande - Ciujung & $52.20-60.00$ & 135 & 19 & 42 & 81 \\
\hline Ciujung - Serang Timur & $60.00-72.00$ & 123 & 2 & 37 & 72 \\
\hline Serang Timur - Serang Barat & $72.00-77.60$ & 44 & 1 & 15 & 19 \\
\hline Serang Barat - Cilegon Timur & $77.60-87.10$ & 45 & 2 & 11 & 17 \\
\hline Cilegon Timur - Cilegon Barat & $87.10-94.80$ & 22 & 0 & 5 & 9 \\
\hline Cilegon Barat - Merak & $94.80-98.10$ & 17 & 0 & 6 & 7 \\
\hline
\end{tabular}

Oleh karena itu, perlu dilakukan audit keselamatan jalan guna mengurangi potensi terjadinya kecelakaan dijalan tol (Agus Taufik Mulyono, et al, 2016). Audit Keselamatan yang akan diterapkan adalah Pro-Active yaitu lebih berorientasi kepada upaya pencegahan atau menghindari (to prevent) kecelakaan. Tapi pada kondisi faktualnya pedoman audit untuk jalan tol itu sendiri belum ada sehingga pedoman yang digunakan adalah untuk jalan nasional yang tidak seluruhnya bisa diterapkan dijalan tol, serta standar dan kriteria untuk jalan tol di Indonesia sendiri masih dalam proses revisi (Rudy Hermawan, 2007). Sehingga perlu langkah - langkah konsisten dan kerjasama institusi terkait secara berkelanjutan untuk perbaikan yang signifikan (Sutandi dan Santosa, 2014, Bagi dan Kumar, 2012 \& Elvebakk, 2015). Menurut Mulyono, et al., (2009), hasil audit dihitung dengan indikator nilai risiko penanganan difisiensi hasil audit keselamatan jalan menunjukkan bahwa beberapa bagian fasilitas jalan berada dalam kategori "bahaya" atau "sangat bahaya".

\section{METODE PENELITIAN}

\section{Tahapan penelitian}

Sebagai panduan dalam proses penelitian agar penelitian yang dilaksanakan dapat berjalan dengan baik dan sistematis, maka perlu dibuat alur penelitian untuk menjadi panduan dalam pelaksanaan penelitian. Alur penelitian dapat dilihat seperti gambar 1. 


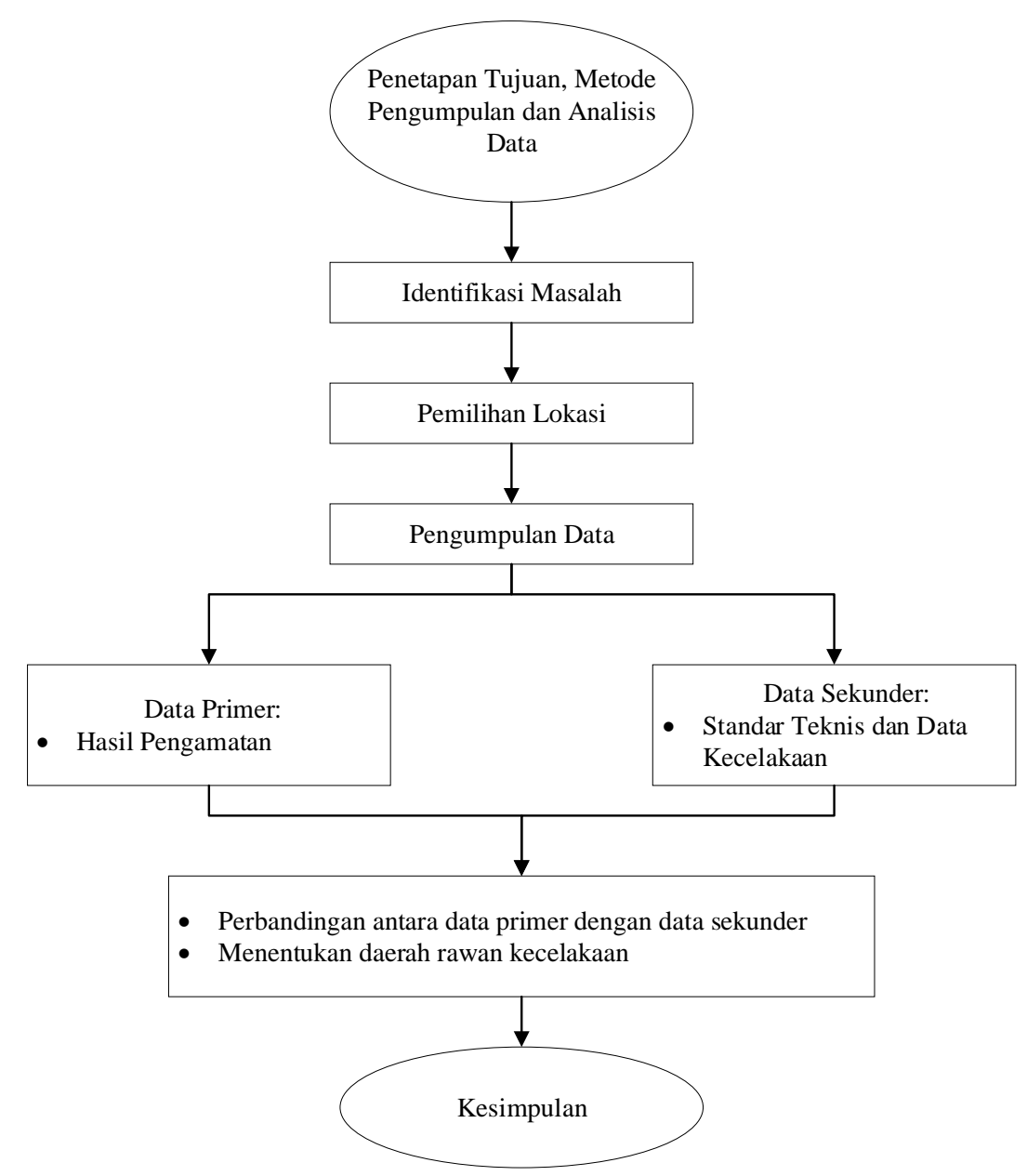

Gambar 1. Tahapan Penelitian

\section{Metode penelitian}

Adapun metode yang digunakan dalam penelitian ini ada 4 langkah penting yaitu:

1. Metode survei lapangan (observasi) dengan melihat dan meneliti secara langsung kondisi jalan sesuai lokasi yang ditentukan dengan memperhatikan segala aspek, yakni geometrik, perkerasan, bangunan pelengkap jalan dan perlengkapan jalan.

2. Metode nilai angka kecelakaan/ Equivalent Accident Number (EAN) /AEK (Angka ekivalen Kecelakaan) dilanjutan dengan metode UCL (Upper Control Limit) - BKA (Batas Kontrol Atas) untuk mendapatkan daerah rawan kecelakaan dari data kecelakaan lalu lintas.

3. Menganalisis data dari hasil observasi langsung dengan dibandingkan dengan standar teknis sesuai ketentuan yang berlaku.

4. Menganalisis data kecelakaan lalu lintas yang didapat dari kepolisian / PT Marga Mandalasakti dengan metode EAN dilanjutkan dengan UCL - BKA untuk menentukan area rawan kecelakaan.

\section{Pengumpulan data}

Data yang dikumpulkan dibagi menjadi 2 bagian, yaitu data primer dan data sekunder. Data primer adalah data survei dengan observasi lapangan yang dilakukan di lokasi ruas jalan yang sudah ditentukan. Untuk observasi lapangan, data akan diambil dengan direkam menggunakan kamera GoPro dengan sudut angle minimal $135^{\circ}$ dan diteliti kembali dari hasil video dengan memperhatikan aspek geometrik, perkerasan, bangunan pelengkap jalan dan perlengkapan jalan. 


\section{HASIL DAN PEMBAHASAN}

Untuk menentukan daerah rawan kecelakaan digunakan metode EAN (Equivalent Accident Number / AEK (Angka Ekivalen Kecelakaan) (Pignataro, 1973 dan Sugiyanto, \& Fadli, 2013), yang merupakan pembobotan angka ekivalen kecelakaan mengacu pada biaya kecelakaan lalu lintas. AEK dihitung dengan menjumlahkan kejadian kecelakaan pada setiap kilometer panjang jalan kemudian dikalikan dengan nilai bobot sesuai tingkat keparahan. Nilai bobot standar yang digunakan adalah Meninggal dunia $(\mathrm{MD})=12$, Luka berat $(\mathrm{LB})=6$, Luka ringan $(\mathrm{LR})=3$, Kerusakan kendaraan $(K)=1$, (Soemitro, 2005). Dimana dinyatakan dalam rumus:

$\mathrm{EAN}=12 \mathrm{MD}+6 \mathrm{LB}+3 \mathrm{LR}+1 \mathrm{~K}$

Penentuan lokasi rawan kecelakaan dilakukan berdasarkan angka kecelakaan tiap kilometer jalan yang memiliki nilai bobot AEK melebihi nilai batas tertentu. Nilai batas ini dapat dihitung antara lain dengan menggunakan metode Batas Kontrol Atas (BKA) dan Upper Control Limit (UCL). Nilai Batas Kontrol Atas (BKA) ditentukan dengan menggunakan persamaan berikut:

$\mathrm{BKA}=\mathrm{C}+3 \sqrt{C}$

dengan $\mathrm{C}=\mathrm{Rata}-$ rata angka kecelakaan EAN

Nilai UCL (Upper Control Limit) ditentukan dengan menggunakan persamaan berikut:

$\mathrm{UCL}=\lambda+\psi+\sqrt{(\lambda / \mathrm{m})+(0.829 / \mathrm{m})+[1 /(2 / \mathrm{m})]}$

dengan: $\lambda=$ Rata-rata angka kecelakaan EAN;

$\Psi=$ Faktor probabilitas $=2.576 \mathrm{~m}=$ Angka kecelakaan ruas yang ditinjau $($ AEK $)$

Metode Upper Control Limit (UCL) dan Batas Kontrol Atas (BKA) akan digunakan untuk menentukan lokasi titik rawan kecelakaan lalu lintas. Suatu ruas jalan atau segmen akan diidentifikasi sebagai lokasi titik rawan kecelakaan lalu lintas jika jumlah angka ekivalen kecelakan lebih besar dibandingkan dengan nilai UCL atau nilai BKA.

\section{Hasil analisis pengamatan langsung}

Tabel 2. Hasil Analisis Pengamatan Langsung

\begin{tabular}{clll}
\hline $\begin{array}{c}\text { KM. (arah Merak } \\
\text { Tanggerang) }\end{array}$ & \multicolumn{1}{c}{ Kondisi Jalan } & Kondisi Perkerasan & Rambu \\
\hline $92.40-92.10$ & Tikungan ke kanan & $\begin{array}{l}\text { Jalan tidak rata dan ada } \\
\text { retak }\end{array}$ & Tidak ada \\
\hline $94.00-94.50$ & Tikungan ke kiri & Jalan sudah rata dan halus & $\begin{array}{l}\text { Peringatan tikungan ke } \\
\text { kiri }\end{array}$ \\
\hline $68.90-68.50$ & $\begin{array}{l}\text { Tikungan ke kiri dan } \\
\text { menanjak }\end{array}$ & Jalan sudah rata dan halus & $\begin{array}{l}\text { Peringatan tikungan ke } \\
\text { kiri }\end{array}$ \\
\hline $39.00-42.30$ & Tikungan ke kiri & $\begin{array}{l}\text { Jalan tidak rata dan } \\
\text { bergelombang }\end{array}$ & $\begin{array}{l}\text { kecepatan minimum 40, } \\
\text { maksimal 80 }\end{array}$ \\
\hline $41.50-42.00$ & Tikungan ke kiri & Jalan sudah rata dan halus & Tidak ada \\
\hline
\end{tabular}




\begin{tabular}{|c|c|c|c|}
\hline $64.60-70.30$ & Lurus & $\begin{array}{l}\text { Jalan tidak rata dan } \\
\text { bergelombang }\end{array}$ & Tidak ada \\
\hline
\end{tabular}

Dari Tabel 2 dapat dilihat beberapa ruas yang memiliki kekurangan rambu yaitu pada ruas jalan Km. 92.40 - 92.10 arah Merak - Tangerang, terdapat tikungan ke kanan tetapi tidak terdapat peringatan rambu untuk menikung ke kanan, sehingga akan rawan terjadi kecelakaan. Demikian juga dari arah Tangerang - Merak pada Km. 41.50-42.00 dan Km. 64.60 - 70.30 tidak terdapat rambu peringatan menikung ke kiri dan peringatan batas kecepatan. Demikian juga pada kondisi jalan mengalami perubahan menjadi menurun atau menanjak namun tidak ada rambu pemberitahuan pada ruas tersebut. Hal ini tidak sesuai dengan Peraturan Menteri No 13 tahun 2014. Dari tabel 2, juga dapat dilihat ruas yang perkerasannya tidak rata dan bergelombang namun tidak ada rambu peringatan sehingga dapat merupakan faktor surprise hazard bagi pengemudi.

\section{Hasil analisis dengan metode AEK}

Tabel 3. Hasil Perhitungan Metode AEK

\begin{tabular}{|c|c|c|c|c|c|c|c|c|}
\hline \multirow{2}{*}{ Nama Ruas Jalan } & \multirow{2}{*}{$\mathrm{Km}$} & \multirow{2}{*}{$\begin{array}{c}\text { Total } \\
\text { Kecelakaan }\end{array}$} & \multicolumn{4}{|c|}{ Angka Ekuivalen Kecelakaan } & \multirow{2}{*}{ UCL } & \multirow{2}{*}{ BKA } \\
\hline & & & $12 \mathrm{xMD}$ & $6 x L B$ & $3 \times \mathrm{xLR}$ & TOTAL & & \\
\hline $\begin{array}{c}\text { Cikupa - Balaraja } \\
\text { Timur }\end{array}$ & $\begin{array}{c}31.40 \\
- \\
36.10 \\
\end{array}$ & 79 & 24 & 90 & 87 & 201 & 293.6745744 & 316.8610379 \\
\hline $\begin{array}{c}\text { Balaraja Timur - } \\
\text { Balaraja Barat }\end{array}$ & $\begin{array}{c}36.10 \\
- \\
38.90\end{array}$ & 86 & 36 & 108 & 102 & 246 & 296.3654561 & 316.8610379 \\
\hline $\begin{array}{c}\text { Balaraja Barat - } \\
\text { Cikande }\end{array}$ & $\begin{array}{c}38.90 \\
- \\
52.20 \\
\end{array}$ & 106 & 72 & 120 & 171 & 363 & 302.4235254 & 316.8610379 \\
\hline $\begin{array}{c}\text { Cikande - } \\
\text { Ciujung }\end{array}$ & $\begin{array}{c}52.20 \\
- \\
60.00 \\
\end{array}$ & 135 & 228 & 252 & 243 & 723 & 316.6018305 & 316.8610379 \\
\hline $\begin{array}{c}\text { Ciujung - Serang } \\
\text { Timur }\end{array}$ & $\begin{array}{c}60.00 \\
- \\
72.00 \\
\end{array}$ & 123 & 24 & 222 & 216 & 462 & 306.8340753 & 316.8610379 \\
\hline
\end{tabular}

Tabel 3. Hasil Perhitungan Metode AEK (Lanjutan)

\begin{tabular}{|c|c|c|c|c|c|c|c|c|}
\hline \multirow{2}{*}{ Nama Ruas Jalan } & \multirow{2}{*}{$\mathrm{Km}$} & \multirow{2}{*}{$\begin{array}{c}\text { Total } \\
\text { Kecelakaan }\end{array}$} & \multicolumn{4}{|c|}{ Angka Ekuivalen Kecelakaan } & \multirow{2}{*}{ UCL } & \multirow{2}{*}{ BKA } \\
\hline & & & $12 \mathrm{xMD}$ & $6 x L B$ & $3 x L R$ & TOTAL & & \\
\hline $\begin{array}{l}\text { Serang Timur - } \\
\text { Serang Barat }\end{array}$ & $\begin{array}{c}72.00 \\
- \\
77.60 \\
\end{array}$ & 44 & 12 & 90 & 57 & 159 & 290.8999181 & 316.8610379 \\
\hline $\begin{array}{l}\text { Serang Barat - } \\
\text { Cilegon Timur }\end{array}$ & $\begin{array}{c}77.60 \\
- \\
87.10\end{array}$ & 45 & 24 & 66 & 51 & 141 & 289.6128112 & 316.8610379 \\
\hline $\begin{array}{c}\text { Cilegon Timur - } \\
\text { Cilegon Barat }\end{array}$ & $\begin{array}{c}87.10 \\
- \\
94.80\end{array}$ & 22 & 0 & 30 & 27 & 57 & 282.5633685 & 316.8610379 \\
\hline $\begin{array}{c}\text { Cilegon Barat - } \\
\text { Merak }\end{array}$ & $\begin{array}{c}94.80 \\
- \\
98.10\end{array}$ & 17 & 0 & 36 & 21 & 57 & 282.5633685 & 316.8610379 \\
\hline
\end{tabular}

Dari tabel 3 di atas dapat dilihat ruas jalan yang memiliki nilai EAN tertinggi adalan Balaraja Barat - Cikande, Cikande - Ciujung dan Ciujung - Tanggerang Timur. Cikande - Ciujung memiliki fatalitas kecelakaan tertinggi dengan jumlah korban meninggal dunia 19 orang, jumlah korban 
luka berat 42, dan jumlah korban luka ringan 81 orang. Nilai angka ekivalen dihitung sebagai berikut:

$A E K=12 \times M D+6 \times L B+3 \times L R$

$A E K=(12 * 19)+(6 * 42)+(3 * 81)=723$

Jumlah hasil perhitungan angka ekivalen kecelakaan (m) di ruas Cikande - Ciujung adalah 723. Setelah semua nilai AEK dihitung maka langkah selanjutnya yaitu mencari nilai rata-rata kecelakaan $(\lambda)$ yang diperoleh dari jumlah nilai AEK dibagi dengan jumlah ruas jalan. Nilai ratarata kecelakaan $(\lambda)$ pada tahun 2018 sebesar $2409 / 9=267.77$. Perhitungan nilai batas dilakukan untuk mengetahui batas tingkat kerawanan kecelakaan tiap ruas jalan, dimana setiap ruas jalan memiliki batas tingkat kerawanan kecelakaan yang berbeda-beda.

Perhitungan ini menjadi acuan untuk menentukan ruas jalan yang termasuk daerah rawan kecelakaan di ruas jalan tol Tangerang-Merak. Contoh perhitungan nilai UCL (Upper Control Limit) pada ruas jalan Cikande - Ciujung dengan data angka kecelakaan rata-rata $(\lambda)=267.77$; nilai faktor probabilitas $(\Psi)=2,576$, dan jumlah angka ekivalen kecelakaan $(\mathrm{m})=723$. Diperoleh nilai upper control limit ruas jalan Cikande - Ciujung $=316.6018305$. Nilai batas kontrol atas diperoleh dengan memasukkan nilai rata-rata angka ekivalen kecelakaan pada tahun 2018 sebesar 267.77 ke Persamaan dan diperoleh nilai BKA $=316.8610379$.

\section{KESIMPULAN DAN SARAN}

\section{Kesimpulan}

1. Dari hasil oberservasi secara langsung, kondisi eksisting geometrik sudah baik namun masih ada beberapa ruas yang perkerasannya banyak memiliki tambalan dan bergelombang sehingga mengurangi kenyamanan pengemudi. Untuk bangunan pelengkap sudah cukup baik walaupun terdapat kurangnya rambu pada beberapa ruas jalan, terutama rambu peringatan tikungan sedikit di jalan Tol Tangerang-Merak.

2. Dari hasil analisis data kecelakaan lalu lintas, dapat disimpulkan lokasi rawan kecelakaan lalu lintas diperoleh untuk tahun 2018 adalah terdapat tiga ruas jalan yaitu ruas Balaraja Barat Cikande (Km36+100 - Km38+900), Cikande - Ciujung (Km38+900 - Km52+200), Ciujung - Serang Timur (Km52+200 - Km60+00). Itu menunjukkan bahwa ketiga ruas tersebut merupakan black area pada jalan tol Tangerang-Merak.

3. Dengan membandingkan dengan observasi langsung, maka dapat dilihat bahwa pada ruas jalan Tangerang - Merak terdapat beberapa titik yang rambu jalannya tidak lengkap pada jalan menikung, menanjak dan menurun.

4. Pada ruas Cikande - Ciujung Km39+00 sampai Km39+500, Km52+200 memiliki perkerasan yang tidak rata dan bergelombang, serta dengan perkerasan yang bergelombang akibat bekas tambalan (pathcing)

\section{Saran}

Setelah penelitian ini selesai dibuat, penulis ingin memberikan saran untuk penelitian lebih lanjut, yaitu:

1. Melaksanakan survei awal dengan lebih seksama sehingga semua langkah antisipasi kesalahan pada observasi langsung dapat dicegah. 
2. Menggunakan kamera yang lebih baik untuk pengambilan gambar bangunan pelengkap jalan di jalan tol agar bisa meliput minimal $135^{\circ}$ sudut pandang dengan memori kamera yang besar sehingga semua data lapangan dapat terekam.

\section{REFERENSI}

Bagi, S., \& Kumar, D. (2012). Road Safety Audit. IOS Journal of Mechanical and Civil Engineering (IOSRJMCE), 1-8.

Duddu, V. R., Kukkapalli, V. M., \& Pulugurtha, S. S. (2019). Crash risk factors associated with injury severity of teen drivers. IATSS Research, 37-43.

Elvebakk, B. (2015). Paternalism and acceptability in road safety work. Safety Science, 298-304.

Firgian, H., Sulandari, E., \& Mayuni, S. (2014). EVALUASI KEBERADAAN RAMBU DAN MARKA JALAN DI KOTA PONTIANAK. Jurnal Mahasiswa Teknik Sipil Universitas Tanjungpura, 1-14.

Fuller, R. (2005). Towards a general theory of driver behaviour. Accident Analysis \& Behaviour, 461-472.

Idalin, F., Malkhamah, S., \& Suparma, L. B. (2018). PENGEMBANGAN METODE PREDIKSI PROBABILITAS KECELAKAAN PADA SUATU RUAS JALAN ANTARKOTA BERDASARKAN KONDISI GEOMETRIK JALAN DAN KARAKTERISTIK LALU LINTAS. Jurnal Transportasi, 145-152.

Marga, D. B. (2007). Penyusunan Sistem Manajemen dan Pedoman Keselamatan Jalan dalam Kegiatan Pembangunan Jalan. Jakarta: Departemen Pekerjaan Umum.

Marwoto, Yulipriyono, E. E., \& Siswanto, J. (2009). ANALISIS KECELAKAAN LALU LINTAS JALAN TOL KRAPYAK - SRONDOL, SEMARANG. Jurnal Studi Kecelakaan Lalu Lintas, 25-30.

Mulyono, A., Berlian, K., \& Gunawan, H. (2009). Audit Keselamatan Infrastruktur Jalan (Studi Kasus Jalan Nasional KM78-KM79 Jalur Pantura Jawa, Kabupaten Batang). Jurnal Teknik Sipil, 163-174.

Radiansyah, S., Mulyana, N., \& Krisnani, H. (2017). DAMPAK PEMBANGUNAN RUAS TOL CIPULARANG "PENDEKATAN SISTEM SEBAGAI SEBUAH TAWARAN SOLUSI". Jurnal Penelitian \& PPM, 129-389.

Rochaety, E., Tresnati, R., \& Latief, M. A. (2007). Metodologi Penelitian Bisnis: Dengan Aplikasi SPSS. Jakarta: Mitra Wacana Media.

Roseily, S. (2013). EVALUASI PRIORITAS SPM (STANDAR PELAYANAN MINIMAL) JALAN TOL JAKARTA-TANGERANG MELALUI PEMBOBOTAN DENGAN METODE ANALYTICAL HIERARCHY PROCESS. Jakarta: Universitas Bina Nusantara.

Sugiyanto, G., \& Fadli, A. (2013). Identifikasi Lokasi Rawan Kecelakaan Lalu Lintas Dengan Metode Batas Kontrol Atas Dan Upper Control Limit. Jurnal Teknik SIpil dan Perencanaan.

Sutandi, A. C., \& Santosa, W. (2013). Road Safety Improvement in Developing Country Case Study on National Road in Indonesia. Eastern Asia Society for Transportation Studies International Conference. Taipei. 
Treat, J., Tumbas, N., McDonald, S., Shinar, D., Hume, R., Mayer, R., . . Castellan, N. (1979). TRI-LEVEL STUDY OF THE CAUSES OF TRAffiC ACCIDENTS: FINAL REPORT. Bloomington: Institute for Research in Public Safety Indiana University.

Zulhendra. (2015). ANALISIS TINGKAT KECELAKAAN LALU LINTAS PADA RUAS JALAN. ROKAN HULU: PROGRAM SETUDI TEKNIK SIPIL UNIVERSITAS PASIR PENGARAIAN. 
